\title{
Reevaluation of immune activation in the era of cART and an aging HIV-infected population
}

\author{
Lesley R. de Armas, ${ }^{1}$ Suresh Pallikkuth, ${ }^{1}$ Varghese George, ${ }^{1}$ Stefano Rinaldi, ${ }^{1}$ Rajendra Pahwa, ${ }^{1}$ \\ Kristopher L. Arheart, ${ }^{2}$ and Savita Pahwa' \\ 'Department of Microbiology and Immunology, and ${ }^{2}$ Department of Epidemiology and Public Health, Division of \\ Biostatistics, University of Miami Miller School of Medicine, Miami, Florida, USA.
}

\begin{abstract}
Biological aging is associated with immune activation (IA) and declining immunity due to systemic inflammation. It is widely accepted that HIV infection causes persistent IA and premature immune senescence despite effective antiretroviral therapy and virologic suppression; however, the effects of combined HIV infection and aging are not well defined. Here, we assessed the relationship between markers of IA and inflammation during biological aging in HIV-infected and -uninfected populations. Antibody response to seasonal influenza vaccination was implemented as a measure of immune competence and relationships between IA, inflammation, and antibody responses were explored using statistical modeling appropriate for integrating high-dimensional data sets. Our results show that markers of IA, such as coexpression of HLA antigen D related (HLA-DR) and CD38 on $\mathrm{CD}^{+} \mathrm{T}$ cells, exhibit strong associations with HIV infection but not with biological age. Certain variables that showed a strong relationship with aging, such as declining naive and CD38+ CD4 and CD8+ $\mathrm{T}$ cells, did so regardless of HIV infection. Interestingly, the variable of biological age was not identified in a predictive model as significantly impacting vaccine responses in either group, while distinct IA and inflammatory variables were closely associated with vaccine response in HIVinfected and -uninfected populations. These findings shed light on the most relevant and persistent immune defects during virological suppression with antiretroviral therapy.
\end{abstract}

Conflict of interest: The authors have declared that no conflict of interest exists.

Submitted: June 21, 2017 Accepted: September 20, 2017 Published: October 19, 2017

Reference information: JCI Insight. 2017;2(20):e95726. https://doi.org/10.1172/jci. insight.95726

\section{Introduction}

Due to advances in combination antiretroviral therapy (cART), many HIV-infected individuals, especially those living in resource-rich settings, are surviving to old age. Despite virologic control of HIV, individuals on cART are susceptible to aging-associated diseases such as cardiovascular disease, kidney disease, neurocognitive decline, and cancer at earlier ages (1), suggesting premature aging in this population. Epigenetic modeling studies on blood cells have shown that cART-treated HIV-infected individuals display an approximately 5-year age acceleration compared with healthy controls $(2,3)$. Correlates of non-AIDS morbidity and mortality in cART-treated $\mathrm{HIV}^{+}$individuals include markers of innate and adaptive immune activation (IA) and inflammation, which can persist despite cART-induced recovery of $\mathrm{CD}^{+} \mathrm{T}$ cell counts (4-6). Innate biomarkers of nonAIDS morbidity and mortality include serum proteins such as interleukin-6 (IL-6), C-reactive protein (CRP), and D-dimer $(7,8)$. Microbial translocation contributes to persistent IA in chronic HIV infection, and the biomarkers associated with it such as lipopolysaccharide (LPS), bacterial DNA, and markers of monocyte activation (e.g., soluble CD14) strongly associate with mortality and do not completely normalize under cART (9, 10). Adaptive markers of chronic IA are often limited to coexpression of HLA antigen D related (HLA-DR) and CD38 on the surface of $\mathrm{T}$ lymphocytes whose relative expression levels, especially on $\mathrm{CD} 8^{+} \mathrm{T}$ cells, correlate with disease progression in untreated HIV infection, microbial translocation, and inflammation (10-13) As with all measurements of IA, cART initiation leads to a decrease in CD $38^{+} \mathrm{HLA}_{-} \mathrm{DR}^{+} \mathrm{T}$ cells, although they are maintained at higher frequencies compared with HIV-uninfected individuals $(4,6,14)$.

Biological aging is also associated with declining immunity and thus shares certain characteristics with chronic HIV infection. Aging-associated immune dysfunction in the general population is often termed immune senescence and refers to a collection of immune defects affecting multiple cell types that have been observed mostly in cohorts of very old individuals ( $>80$ years). With regard to T cells, immune senescence is 
Table 1. Study participant characteristics

\begin{tabular}{lcccccc}
\hline & \multicolumn{3}{c}{ HIV Negative } & \multicolumn{3}{c}{ HIV Positive } \\
& Young & Middle & Old & Young & Middle & Old \\
Number of Individuals & $\mathbf{4 2}$ & $\mathbf{5 7}$ & $\mathbf{4 2}$ & $\mathbf{2 8}$ & $\mathbf{6 7}$ & $\mathbf{4 5}$ \\
$\begin{array}{l}\text { Female, } \boldsymbol{n} \text { (\%) } \\
\text { Age, years }\end{array}$ & 50 & 46 & 40 & 39 & 45 & 31 \\
$\begin{array}{l}\text { Mean } \\
\text { Range }\end{array}$ & 30.1 & 51.4 & 65.1 & 29.3 & 51.5 & 64.9 \\
\hline
\end{tabular}

$\begin{array}{llccccc}\text { Duration of ART, years } & & & & & & \\ \text { Available data, } \boldsymbol{n} & \text { N/A } & \text { N/A } & \text { N/A } & 17 & 45 & 35 \\ \text { Mean } & & & 5.94 & 11.11 & 12.69 \\ \text { Range } & & & 2-14 & 2-29 & 2-27\end{array}$

\section{Ethnicity, $\boldsymbol{n}(\%)$}

$\begin{array}{lcccccc}\text { Hispanic } & 38 & 30 & 31 & 43 & 24 & 27 \\ \text { Non-Hispanic } & 57 & 65 & 60 & 57 & 76 & 64 \\ \text { Not Specified } & 5 & 5 & 9 & 0 & 0 & 9\end{array}$

\begin{tabular}{|c|c|c|c|c|c|c|}
\hline \multicolumn{7}{|l|}{ Race, n (\%) } \\
\hline White & 48 & 42 & 55 & 32 & 27 & 31 \\
\hline Black & 38 & 54 & 33 & 61 & 72 & 67 \\
\hline Asian & 12 & 2 & 12 & 0 & 0 & 0 \\
\hline Not Specified & 2 & 2 & 0 & 7 & 1 & 2 \\
\hline
\end{tabular}
and vaccine-induced $\mathrm{Ab}$ production in postmenopausal women (22). The findings presented herein demonstrate that a core IA and inflammatory signature of aging is unaltered during treated HIV infection, and additionally that HIV infection drives IA independently of biological age even in the context of viral suppression with cART. Using modeling, we further show that in HIV-infected individuals, IA profiles in $\mathrm{T}$ cells can predict low $\mathrm{Ab}$ responses to influenza vaccination.

\section{Results}

$\mathrm{CD}^{+} / \mathrm{CD}^{+}$ratios are reduced in all age groups in $\mathrm{HIV}^{+}$compared with age-matched controls. Prevaccination data were collected from study participants in order to obtain a cross-sectional analysis of immune status in HIVinfected $\left(\mathrm{HIV}^{+}\right)$and $\mathrm{HIV}$-uninfected (healthy control, $\mathrm{HC}$ ) adults divided into 3 age groups: young, 40 years or younger; middle, 41-59 years; and old, 60 years or older (Table 1). Age, gender, and ethnicity distributions were similar in HIV-infected and -uninfected groups, although race distribution was significantly different with fewer whites in the $\mathrm{HIV}^{+}$group $\left(P<0.05\right.$ by Student's $t$ test). The $\mathrm{CD}^{+} / \mathrm{CD}^{+}$ratio is a marker of immune dysfunction in the general population as well as in HIV-infected individuals (23); therefore, we first evaluated $\mathrm{CD}^{+}$and $\mathrm{CD} 8^{+} \mathrm{T}$ cell counts and calculated the $\mathrm{CD} 4^{+} / \mathrm{CD} 8^{+}$ratio. Absolute $\mathrm{CD} 4^{+} \mathrm{T}$ cell counts were significantly reduced in $\mathrm{HIV}^{+}$in the middle and old age groups and $\mathrm{CD}^{+}$count showed an inverse correlation with biological age in the $\mathrm{HIV}^{+}$group only (Figure $1 \mathrm{~A}$ ). Meanwhile, $\mathrm{CD}^{+} \mathrm{T}$ cell counts were significantly elevated in $\mathrm{HIV}^{+}$compared with $\mathrm{HC}$ in all age groups (Figure $1 \mathrm{~B}$ ). The $\mathrm{CD} 4^{+} / \mathrm{CD} 8^{+}$ratio was significantly reduced in all age groups for $\mathrm{HIV}^{+}$compared with $\mathrm{HC}$ but did not show a correlation with biological age in either $\mathrm{HIV}^{+}$or $\mathrm{HC}$ (Figure $1 \mathrm{C}$ ).

$C D 4^{+} T$ cell compartment subset distribution changes with aging. We evaluated the effects of aging and HIV infection on frequencies and distribution of $\mathrm{CD}^{+} \mathrm{T}$ cell maturation subsets (naive, $\mathrm{N}$; central memory, TCM; transitional memory, TTM; effector memory, TEM; and effector, TEff) by multiparameter flow cytometry in the participant groups (Figure $2 \mathrm{~A}$ ). In $\mathrm{HC}$ and $\mathrm{HIV}^{+}$, the data showed inverse correlations between naive cell frequencies and age (Figure $2 \mathrm{~B}$ ), while positive correlations were observed between memory and terminally differentiated subsets (TEM and TEff) and age (Figure 2, D and E). TTM positively 
A

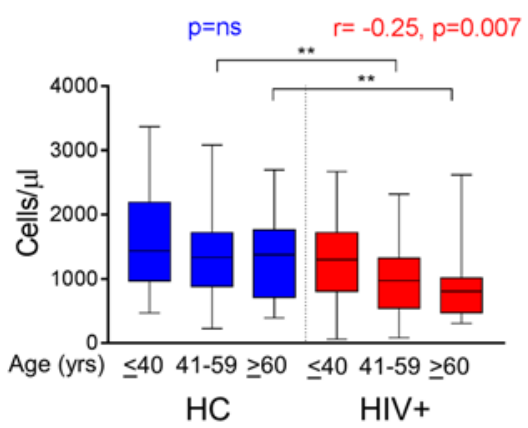

C

\section{CD4/CD8 Ratio}

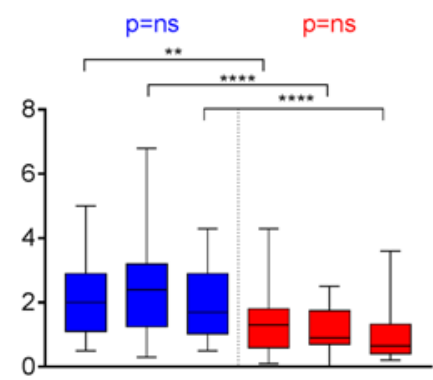

Age (yrs) $\leq 40 \quad 41-59 \geq 60 \leq 40 \quad 41-59 \geq 60$

$\mathrm{HC}$
CD4 Absolute Count
B CD8 Absolute Count

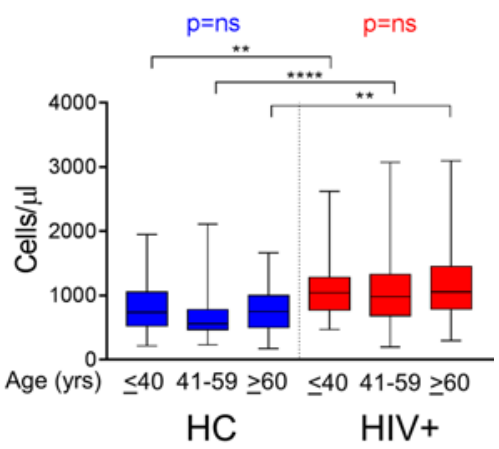

Figure 1. Absolute $\mathrm{CD4}^{+}$and $\mathrm{CD8}^{+} \mathrm{T}$ cell counts by age group. (A) CD4 ${ }^{+} \mathrm{T}$ cell counts, (B) CD8 ${ }^{+} \mathrm{T}$ cell counts, and (C) CD4 ${ }^{+}$I CD8 ${ }^{+}$ratio were calculated per $\mu$ l of whole blood in each age group for HIV-negative (HC) and $\mathrm{HIV}^{+}$groups. Data are shown as box-and-whisker plots and 2-tailed Student's $t$ test was used to measure statistical differences between $\mathrm{HIV}^{+}$and $\mathrm{HC}$. ${ }^{* *} P<0.01,{ }^{* * *} P<0.0001$. Pearson correlation analysis was performed between each measure and biological age (years) and results are designated by blue- or red-font $P$ values for $\mathrm{HC}$ and $\mathrm{HIV}^{+}$groups, respectively. ns, not significant.

correlated with age in $\mathrm{HIV}^{+}$and $\mathrm{TCM}$ did so in $\mathrm{HC}$ (Figure 2, $\mathrm{C}$ and F). The association of TCM and TTM with age was inverted between $\mathrm{HC}$ and $\mathrm{HIV}^{+}$, marked by increased TCM frequencies in $\mathrm{HIV}^{+}$young. Peripheral $\mathrm{T}$ follicular helper ( $\mathrm{pTfh}$ ) cell frequencies (CXCR5 ${ }^{+}$ $\mathrm{TCM}$ ) showed no association with age in $\mathrm{HC}$ or $\mathrm{HIV}^{+}$ groups (Figure 2G).

Markers of IA are elevated on $\mathrm{CD}^{+} T$ cells during controlled HIV infection. To determine the relationships between IA and aging we analyzed the following markers of IA by multiparameter flow cytometry in total $\mathrm{CD} 4^{+}$and $\mathrm{CD} 8^{+} \mathrm{T}$ cells: CD38, HLA-DR, PD-1, ICOS, and Ki-67. CD38 and HLA-DR coexpression marks activated $\mathrm{T}$ cells and is associated with HIV disease progression. PD-1 is an immune checkpoint molecule involved in downregulating immune responses; its expression is induced upon activation in $\mathrm{CD}^{+}$and $\mathrm{CD} 8^{+} \mathrm{T}$ cells (24). ICOS signaling is important for humoral immune responses and has been shown to be upregulated on activated $\mathrm{CD} 4^{+} \mathrm{T}$ cells from HIV-infected patients $(25,26)$. Ki-67 is a nuclear marker of proliferation and activation that has been shown to correlate with $\mathrm{CD} 4^{+}$ $\mathrm{T}$ cell decline during HIV infection (27). We determined whether individual IA marker expression correlates with age in $\mathrm{HC}$ and $\mathrm{HIV}^{+}$groups and evaluated whether HIV status and aging show an interaction with regards to IA marker expression (Table 2). These analyses showed a strong reduction of CD38 expression on CD4 ${ }^{+}$ and $\mathrm{CD} 8^{+} \mathrm{T}$ cells with age and this relationship was independent of HIV infection (Table 2 and Figure $3 \mathrm{~A}$ ). Interestingly, we observed a significant interaction between HIV infection with HLA-DR expression on CD4 ${ }^{+}$ $\mathrm{T}$ cells and age (i.e., increased with age in HIV vs. no change with age in HC, Table 2 and Figure 3B). PD-1 and ICOS expression on $\mathrm{CD} 4^{+}$and $\mathrm{CD} 8^{+} \mathrm{T}$ cells demonstrated moderate positive correlations with age in $\mathrm{HC}$ that were not observed in $\mathrm{HIV}^{+}$, due to higher expression in $\mathrm{HIV}^{+}$young individuals compared with young $\mathrm{HC}$ (Table 2, and Figure 3, C and D). There was also a statistical interaction between HIV infection and the change in ICOS expression with age in $\mathrm{CD} 8^{+} \mathrm{T}$ cells $(P=0.0049)$ and a similar trend was observed in $\mathrm{CD} 4^{+} \mathrm{T}$ cells $(P=0.06)$. Comparison of individual IA marker expression on $\mathrm{CD} 4^{+} \mathrm{T}$ cells in each group showed that $\mathrm{HIV}^{+}$ expressed higher levels of IA markers compared with HC, although the age at which the differences reached significance varied by marker (Figure 3).

Coexpression of CD38 and HLA-DR on $\mathrm{CD}^{+}$and $\mathrm{CD} 8^{+} \mathrm{T}$ cells was not associated with age in either participant group (Figure $4 \mathrm{~A}$ ). However, $\mathrm{HIV}^{+}$exhibited significantly higher frequencies of $\mathrm{CD} 38^{+} \mathrm{HLA}-\mathrm{DR}^{+}$ $\mathrm{CD} 4^{+} \mathrm{T}$ cells compared with $\mathrm{HC}$, while the frequencies of $\mathrm{CD} 38^{+} \mathrm{HLA}-\mathrm{DR} \mathrm{R}^{+} \mathrm{CD} 8^{+} \mathrm{T}$ cells were similar between $\mathrm{HIV}^{+}$and $\mathrm{HC}$. To further investigate IA marker coexpression on $\mathrm{CD}^{+} \mathrm{T}$ cells we performed Boolean combination analysis to assess the frequency of $\mathrm{CD} 4^{+} \mathrm{T}$ cells expressing $5,4,3,2,1$, or none of the 5 markers analyzed (CD38, HLA-DR, PD-1, ICOS, and Ki-67) (Figure 4B). CD38-single-positive cells were removed from the analysis because of their strong relationship with age in both the $\mathrm{HIV}^{+}$and $\mathrm{HC}$ groups (Table 2). In agreement with results showing individual expression of IA markers, in each age group $\mathrm{HIV}^{+}$individuals had higher frequencies of $\mathrm{CD} 4^{+} \mathrm{T}$ cells coexpressing 2 or more IA markers compared with $\mathrm{HC}$ and consequently, fewer cells expressing none of the IA markers. Significant differences were not observed when combination analysis was performed in $\mathrm{CD}^{+} \mathrm{T}$ cells (data not shown). Taken together, these data confirm and extend prior observations that cART-mediated virologic suppression does not fully reverse $\mathrm{IA}$ in $\mathrm{CD} 4^{+} \mathrm{T}$ cells in any age group. 

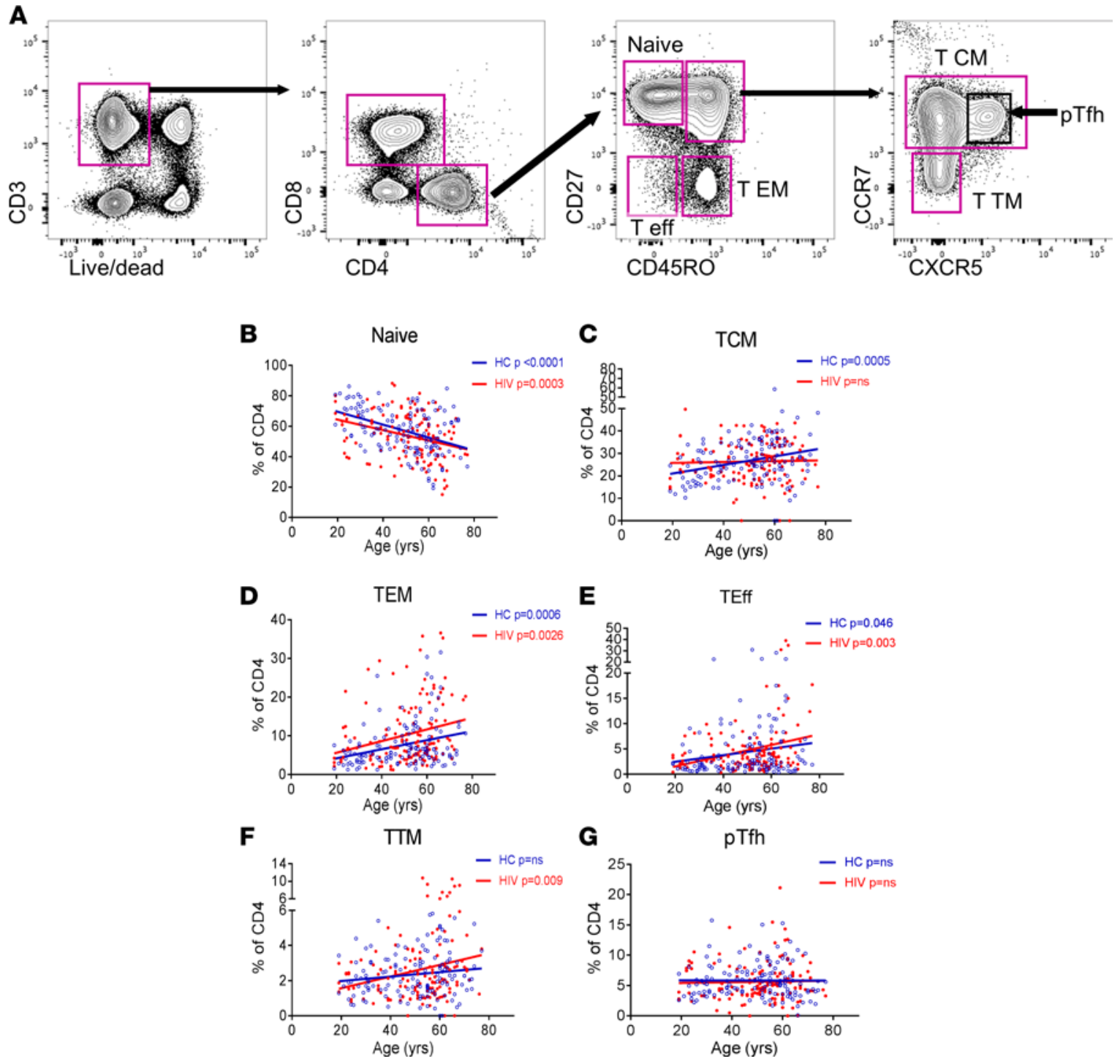

Figure 2. CD4 ${ }^{+} \mathbf{T}$ cell compartment subset distribution during aging and HIV infection. (A) Gating scheme for analysis of CD4 ${ }^{+} T$ cell subsets by multiparameter flow cytometry. (B-C) $x$-y plots are shown plotting biological age (years) and individual CD4+ $T$ cell subset frequencies for each study participant: (B) naive, (C) central memory (TCM), (D) effector memory (TEM), (E) effector (TEff), (F) transitional memory (TTM), and (G) peripheral T follicular helper (pTfh) cells. $P$ values displayed indicate results from linear regression analysis for HIV-negative (blue, HC) and HIV+ (red, HIV) study participants. ns, not significant.

Plasma biomarkers in HIV and aging. In order to address the relationship between T cell IA and markers of inflammation, we quantified levels of soluble proteins in plasma from all study participants and evaluated their relationship to age and HIV infection status (Supplemental Figure 1; supplemental material available online with this article; https://doi.org/10.1172/jci.insight.95726DS1). First, we determined which markers were associated with biological age (Table 3). Six proteins showed significant increases with age in both the $\mathrm{HC}$ and $\mathrm{HIV}^{+}$groups (neopterin, sVCAM, sCD14, sCD163, soluble TNF receptor 1 [sTNFRI], and sTNFRII). Additional biomarkers were associated with age in $\mathrm{HC}$ only (sCD25, MCP1, sICAM, and IL-17A), while IL-8 was uniquely shown to increase with age in $\mathrm{HIV}^{+}$individuals. Next, we compared plasma levels in $\mathrm{HIV}^{+}$relative to $\mathrm{HC}$ individuals by age group (Figure 5). The most significant differences were observed between $\mathrm{HIV}^{+}$and $\mathrm{HC}$ young groups rather than middle and old, and only sTNFRII was significantly elevated in HIV ${ }^{+}$individuals at all ages. In contrast, cytokines IL- 6 and IL-21, and the cardiovascular-related biomarker brain natriuretic peptide (BNP) were lower in $\mathrm{HIV}^{+}$compared with $\mathrm{HC}$ at all ages. These data suggest that the plasma milieu is perturbed by HIV infection and affects the young age group more dramatically than the old when compared with HIV-uninfected individuals. 
Table 2. Correlation of IA marker expression and biological age

\begin{tabular}{|c|c|c|c|c|c|}
\hline & \multicolumn{2}{|c|}{ HIV Negative } & \multicolumn{2}{|c|}{ HIV positive } & \multirow{3}{*}{$\begin{array}{c}\text { Interaction } \\
P \text { value }\end{array}$} \\
\hline & \multicolumn{2}{|c|}{ Correlation with Age } & \multicolumn{2}{|c|}{ Correlation with Age } & \\
\hline & rvalue & $P$ value & r value & $P$ value & \\
\hline \multicolumn{6}{|l|}{ CD4+ $T$ cells } \\
\hline CD38 (\%) & -0.41 & $<0.0001$ & -0.42 & $<0.0001$ & 0.83 \\
\hline HLA-DR (\%) & & 0.45 & 0.36 & $<0.0001$ & 0.0012 \\
\hline PD-1 (\%) & 0.21 & 0.0144 & & 0.10 & 0.63 \\
\hline ICOS (\%) & 0.31 & 0.0003 & & 0.60 & 0.06 \\
\hline Ki-67 (\%) & & 0.62 & & 0.17 & 0.16 \\
\hline \multicolumn{6}{|l|}{ CD8 ${ }^{+} \mathrm{T}$ cells } \\
\hline CD38 (\%) & -0.41 & $<0.0001$ & -0.34 & $<0.0001$ & 0.87 \\
\hline HLA-DR (\%) & 0.17 & 0.05 & 0.30 & 0.0004 & 0.23 \\
\hline PD-1 (\%) & 0.28 & 0.0010 & & 0.40 & 0.18 \\
\hline ICOS (\%) & 0.31 & 0.0003 & & 0.16 & 0.0049 \\
\hline Ki-67 (\%) & & 0.10 & & 0.26 & 0.82 \\
\hline
\end{tabular}

Pairwise correlation analyses were performed using all variables with significant age associations to evaluate how markers of IA and inflammation relate to one another within $\mathrm{HC}$ and $\mathrm{HIV}^{+}$groups. HC exhibited more age-associated variables compared with $\operatorname{HIV}^{+}(22$ vs. 17) but the overall clustering pattern was conserved (Supplemental Figure 2). Naive T cell frequencies and CD38 expression on $\mathrm{CD}^{+} \mathrm{T}$ cells showed strong positive correlation with each other since both variables were reduced in frequency with age, and inverse correlations with all other variables. Although variables from within the same data set showed greater clustering, with flow cytometry data clustering separately from soluble biomarker data, there was a positive albeit weak correlation between cell-associated markers of IA and soluble biomarkers of inflammation in both $\mathrm{HC}$ and $\mathrm{HIV}^{+}$.

$H I V^{+}$individuals exhibit lower TIV response rate and magnitude compared with $H C$. Based on serological $\mathrm{Ab}$ responses to each antigen in seasonal influenza trivalent inactivated vaccine (TIV), wherein a 4-fold increase in titer is considered a positive response, we classified participants based on response to all vaccine antigens as absolute responders or nonresponders, and those with response to only 1 or 2 antigens as other. Mean titers for participants grouped by age and responder status for each antigen before (T0) and after vaccination (T2) are presented in Supplemental Table 1. The distribution analysis showed a decline in absolute responders in

Table 3. Correlation of plasma biomarkers with age in study participants

\begin{tabular}{|c|c|c|c|c|}
\hline & \multicolumn{2}{|c|}{ HIV Negative } & \multicolumn{2}{|c|}{ HIV Positive } \\
\hline & \multicolumn{2}{|c|}{ Correlation with Age } & \multicolumn{2}{|c|}{ Correlation with Age } \\
\hline & r value & $P$ value & r value & $P$ value \\
\hline sCD25 & 0.26 & 0.0009 & & 0.44 \\
\hline MCP1 & 0.25 & 0.001 & & 0.15 \\
\hline sICAM & 0.15 & 0.048 & & 0.22 \\
\hline IL-17A & -0.26 & 0.0007 & & 0.65 \\
\hline IL-8 & & 0.95 & 0.20 & 0.013 \\
\hline Neopterin & 0.31 & $6.86 \times 10^{-5}$ & 0.22 & 0.005 \\
\hline sVCAM & 0.28 & 0.0003 & 0.18 & 0.028 \\
\hline sTNFRI & 0.20 & 0.012 & 0.26 & 0.0009 \\
\hline sTNFRII & 0.20 & 0.01 & 0.21 & 0.011 \\
\hline sCD14 & 0.18 & 0.021 & 0.18 & 0.029 \\
\hline sCD163 & 0.19 & 0.018 & 0.18 & 0.024 \\
\hline
\end{tabular}

IFN- $\gamma$, IL-6, TNF- $\alpha$, D-dimer, LPS, BNP, CRP, and IL-21 did not show a relationship with age in HC or HIV. 
A

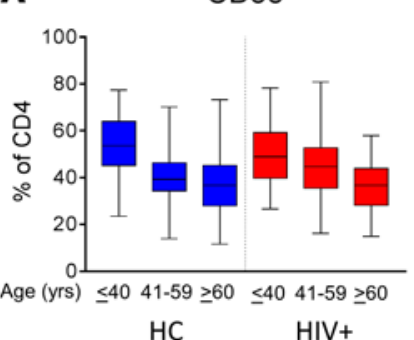

C

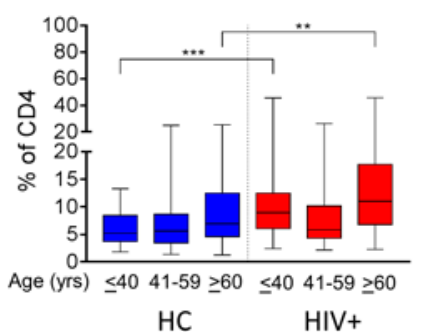

$\mathbf{E}$

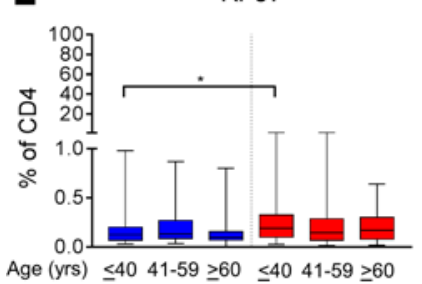

$\mathrm{HC}$
B

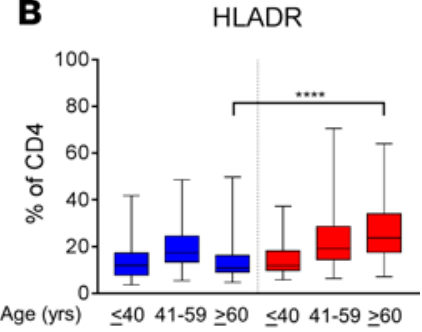

$\mathrm{HC}$

$\mathrm{HIV+}$

D

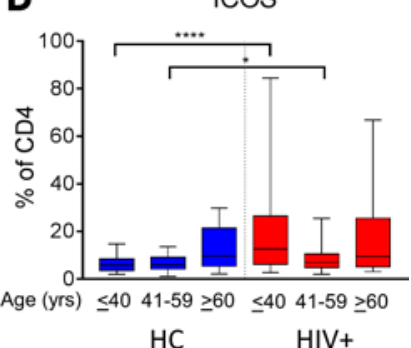

Figure 3. Immune activation markers show higher expression in HIV $^{+}$ groups. Surface expression of (A) CD38, (B) HLA-DR, (C) PD-1, (D) ICOS, and (E) Ki-67 was measured using multiparameter flow cytometry and expressed as percentage positive in total CD4 ${ }^{+} T$ cells by HIV status and age group. Data are shown as box-and-whisker plots and 2-tailed Student's $\mathrm{t}$ test was used to measure statistical differences between $\mathrm{HIV}^{+}$ and HIV-negative (HC) for each age group. ${ }^{*} P<0.05$, ${ }^{* *} P<0.01$, ${ }^{* *} P<$ $0.01,{ }^{* * *} P<0.0001$. Pearson correlation analysis of each marker with age within $\mathrm{HIV}^{+}$and $\mathrm{HC}$ are shown in Table 2.

$\mathrm{HC}$ with age, while in $\mathrm{HIV}^{+}$this pattern was not observed (Figure 6A). Compared with $\mathrm{HC}$, there were fewer absolute responders in $\mathrm{HIV}^{+}$young and middle age groups but in the old age group they were similar. These data suggest the age-dependent decline in vaccine responses observed in $\mathrm{HC}$ and well-documented in the literature (28-30) is perturbed in the setting of chronic HIV infection. We assigned a response score to each participant using the combined fold increase in serum titer for all 3 antigens in order to obtain a scale on which to compare and contrast the participants. Distribution of the score across $\mathrm{HC}$ and $\mathrm{HIV}^{+}$participants revealed that nonresponders had response scores of 3 or lower, while absolute responders had response scores of 4 or higher (Figure $6 \mathrm{~B}$ ). $\mathrm{HIV}^{+}$participants differed from $\mathrm{HC}$ in that they had more individuals in the 2-3 score group and zero individuals in the 7-8 score group, highlighting the enrichment of $\mathrm{HIV}^{+}$individuals with lower $\mathrm{Ab}$ responses to seasonal TIV. Participants who responded to only 1 or 2 strains with a 4-fold increase in Ab titer from T0 to T2 (designated "other") were present throughout the score scale, although these individuals were concentrated in the 3-4 score group in $\mathrm{HC}$ and $\mathrm{HIV}^{+}$, creating a buffer between absolute responders and nonresponders.

LASSO modeling to determine variables associated with TIV response. We used the statistical method LASSO (least absolute shrinkage and selection operator) (31) to generate predictive models and identify which variables in our data set closely associated with response score in $\mathrm{HC}$ and $\mathrm{HIV}^{+}$groups separately. LASSO was selected because it penalizes variables that highly correlate with one another to avoid overfitting the model, which was necessary considering the high degree of correlation among the variables measured including biological age (Supplemental Figure 2). Nineteen plasma biomarker parameters and 111 flow cytometry parameters were entered as $x$ variables for LASSO analysis using the response score as the outcome. These analyses generated models containing unique variables for $\mathrm{HC}$ and $\mathrm{HIV}^{+}$groups that were able to segregate absolute responders and nonresponders (Figure 7, A and B). For HC, 4 variables were selected by the model including frequencies of pTfh, HLA-DR ${ }^{+} \mathrm{CD} 8^{+} \mathrm{T}$ cells, and HLA-DR ${ }^{+} \mathrm{ICOS}^{+} \mathrm{CD} 4^{+} \mathrm{T}$ cells, all of which had a positive association with vaccine response score (Table 4$)$. CD $8^{+} \mathrm{T}$ cell count had a negative association with $\mathrm{Ab}$ responses. In $\mathrm{HIV}^{+}, 8$ variables were selected including plasma levels of IL-21 and sCD25, both of which had a negative association with vaccine response (Table 4). Interestingly, 4 pTfh subsets (defined using Boolean combination analysis of IA marker expression) showed significant associations with vaccine response. The subsets that had negative associations with vaccine response had the phenotype $\mathrm{CD} 38^{+} \mathrm{HLA}-\mathrm{DR}^{+/-} \mathrm{ICOS}^{+/-} \mathrm{Ki}-67^{+} \mathrm{PD}-1^{+}$, while subsets with a positive association had the phenotype CD $38^{+/-} \mathrm{HLA}-\mathrm{DR}^{+/-} \mathrm{ICOS}^{+} \mathrm{Ki}-67^{+} \mathrm{PD}-1^{-}$. Frequencies of CD4 ${ }^{+} \mathrm{TCM}$ cells and CD38-HLA-DR ${ }^{-} \mathrm{CD} 8^{+} \mathrm{T}$ cells both also showed positive associations with vaccine response in $\mathrm{HIV}^{+}$individuals.

\section{Discussion}

The terms IA and inflammation are often used interchangeably when referring to the immunological sideeffects of HIV infection and aging. In this study we sought to shed light on the relationships between IA and inflammation in the context of HIV infection and aging, in order to address challenges associated with a burgeoning population of elderly HIV-infected individuals. We evaluated a broad range of established markers of IA and inflammation and compared and contrasted expression levels within different age groups 
A

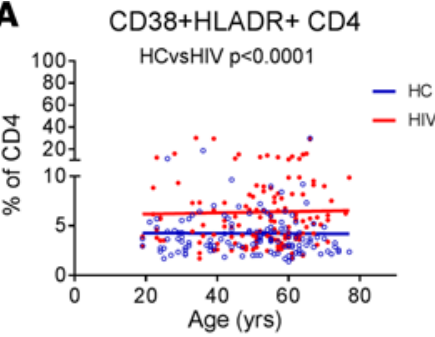

$\mathrm{CD} 38+\mathrm{HLADR}+\mathrm{CD} 8$

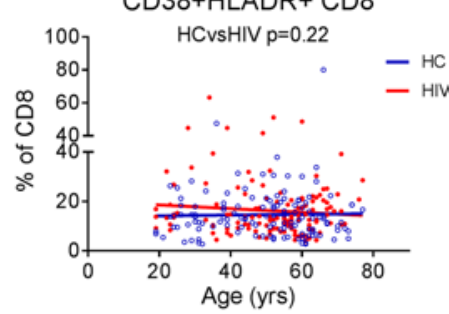

Figure 4. Coexpression of immune activation markers on $\mathrm{CD4}^{+} \mathrm{T}$ cells at higher frequencies in HIV+ individuals compared with HIV negative (HC) regardless of age. (A) The relationship between frequencies of $\mathrm{CD} 38^{+} \mathrm{HLA}-\mathrm{DR}{ }^{+} \mathrm{CD} 4^{+} \mathrm{T}$ cells (left) and $\mathrm{CD} 8^{+} \mathrm{T}$ cells (right) with age (years) is shown. $P$ values indicate results of 2-tailed Student's $t$ test to measure statistical differences between $\mathrm{HIV}^{+}$and $\mathrm{HC}$. (B) Ring graphs represent combination gate (Boolean) analysis using the 5 immune activation markers (CD38, HLA-DR, PD-1, ICOS, Ki-67) on $\mathrm{CD}^{+} \mathrm{T}$ cells. Each ring shows relative frequency of cells expressing $0,1,2,3,4$, or 5 markers simultaneously for each group. Multiple $t$ tests were performed to compare relative frequencies from one ring (i.e., study group) to another. ${ }^{*}$ Indicates significant FDR $<1 \%$ when compared with $\mathrm{HIV}^{+}$group. \#Indicates significant FDR $<1 \%$ when compared with HIV young group.

B

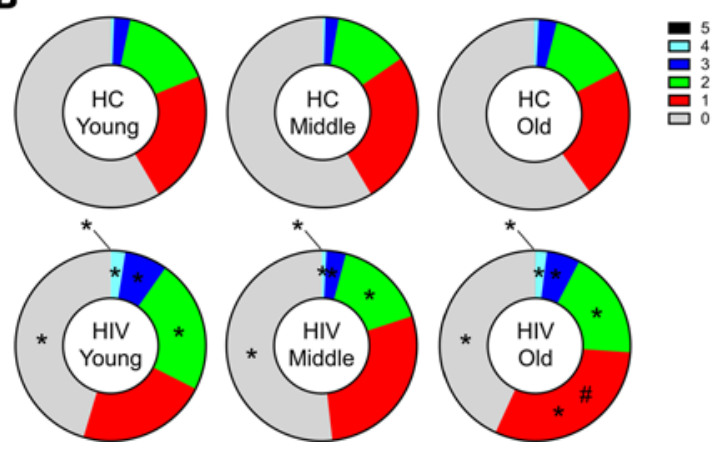

in HIV-infected and -uninfected individuals. Our data revealed a core signature of aging that was unaltered by the presence of chronic HIV infection and included changes in the T cell compartment subset distribution with age and a loss of CD38 expression on $\mathrm{T}$ cells. However, some age-related changes in marker expression were observed only in HIV-negative individuals, including increasing cell-surface expression of PD-1 and ICOS on $\mathrm{CD}^{+}$and $\mathrm{CD} 8^{+} \mathrm{T}$ cells as well as increasing plasma biomarkers sCD25, sICAM, and MCP1. Further analysis showed that

expression levels of these particular markers were already increased in younger $\mathrm{HIV}^{+}$individuals, thereby negating the effect of aging that was observed in HC. These results provide the basis for an immune signature of premature aging in $\mathrm{HIV}^{+}$, even when virological suppression is achieved.

The finding of reduced CD38 expression with age was not unexpected since it is expressed on double-positive thymocytes and thymus function declines steadily through at least age 60 (32). However, CD38 expression on T cells (especially CD8) has also been extensively studied and implicated as a correlate of HIV disease progression (33-35) and further, coexpression with HLA-DR on the surface of $\mathrm{T}$ cells is a widely accepted measure of IA $(9,10,36)$. Therefore, we expected that $\mathrm{HIV}^{+}$would exhibit differential expression patterns of CD38 on T cells compared with HC. The data, however, showed a direct overlap of linear slopes relating CD38 expression and age in $\mathrm{HIV}^{+}$ and $\mathrm{HC}$ groups on $\mathrm{CD}^{+}$and $\mathrm{CD}^{+} \mathrm{T}$ cells. Despite the remarkable overlap, both groups exhibited a broad distribution of CD38 expression within age groups, suggesting that age alone is not driving CD38 expression on $\mathrm{T}$ cells. Furthermore, the reduction in CD38 expression with age seemed to preferentially affect the

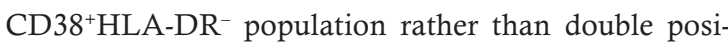
tive $\left(\mathrm{CD} 38^{+} \mathrm{HLA}-\mathrm{DR}^{+}\right)$, which was not associated with age in $\mathrm{CD}^{+}$or $\mathrm{CD}^{+} \mathrm{T}$ cells from either group. Interestingly, the double-positive $\left(\mathrm{CD} 38^{+} \mathrm{HLA}-\mathrm{DR}^{+}\right) \mathrm{T}$ cells were significantly higher in $\mathrm{HIV}^{+}$compared with $\mathrm{HC}$ in the $\mathrm{CD}^{+}$compartment only. This finding was consis-

Figure 5. The effect of HIV on prevaccination plasma biomarkers in study participants by age group. Heatmap showing fold-change difference between $\mathrm{HIV}^{+}$participants and HIV negative (HC) for different age groups. Colored boxes represent significant $(P<0.05)$ differences between $\mathrm{HIV}^{+}$and $\mathrm{HC}$ using 2-tailed Student's $t$ test. Blue color represents lower concentration in $\mathrm{HIV}^{+}$relative to $\mathrm{HC}$, and red color represents higher concentration of the indicated soluble protein in $\mathrm{HIV}^{+}$relative to $\mathrm{HC}$.

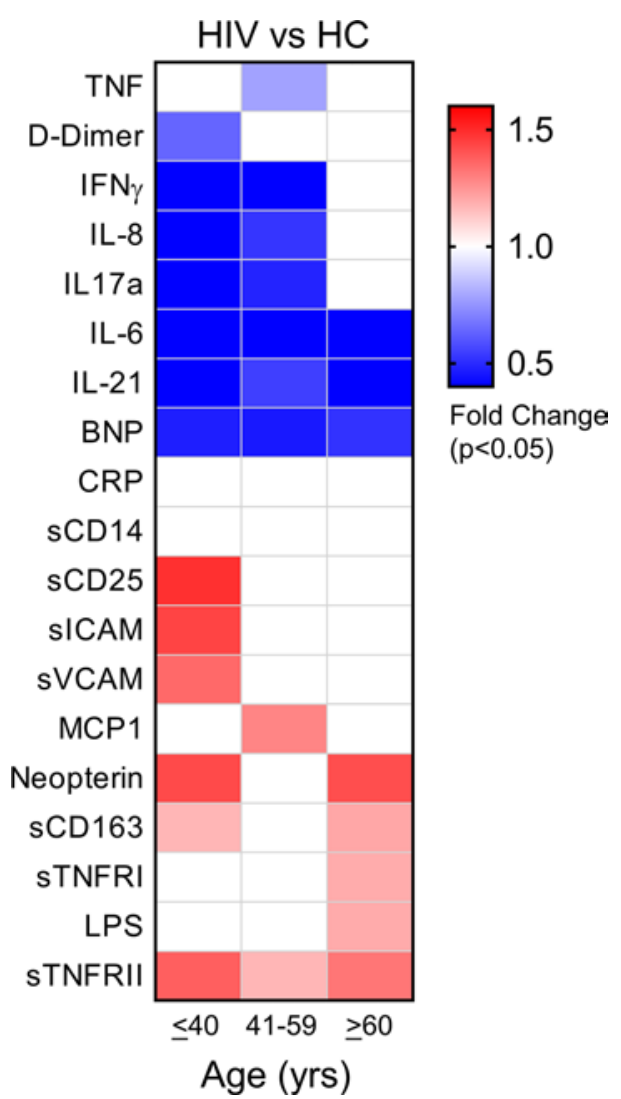


A

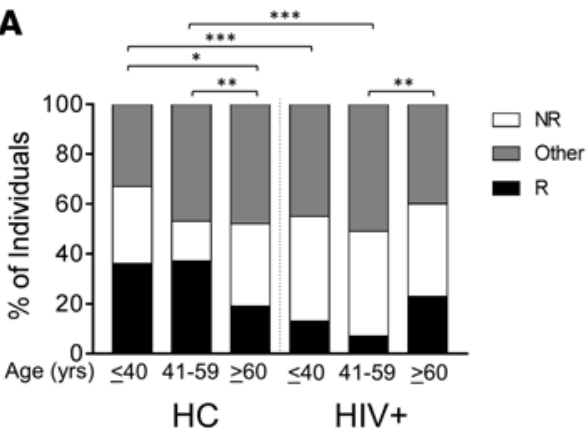

B
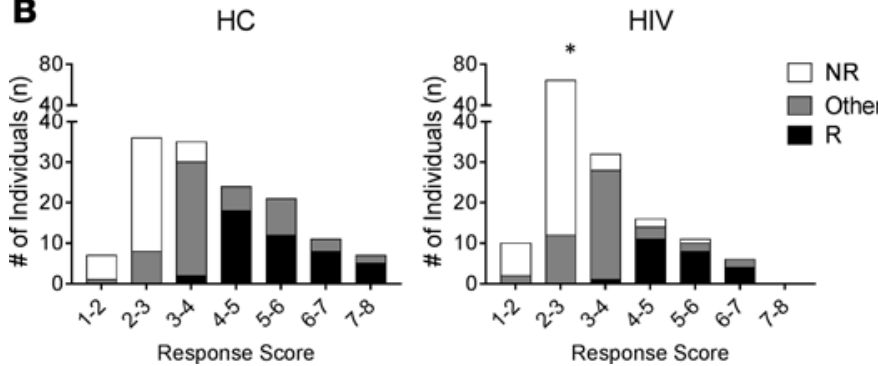

Figure 6. HIV+ individuals have lower response rate and magnitude against trivalent inactivated influenza vaccine compared with HIV negative (HC). (A) Bar graph showing the distribution of absolute responders and nonresponders by age group in $\mathrm{HIV}^{+}$and $\mathrm{HC}$ study participants. $\chi^{2}$ analysis was used to determine differences in responder status between the groups. ${ }^{*} P<0.05,{ }^{* *} P<0.01,{ }^{* * *} P<0.01$. (B) Distribution of response scores in $\mathrm{HC}$ (left) and HIV+ (right) groups. $\chi^{2}$ analysis was performed to compare score distributions between $\mathrm{HC}$ and $\mathrm{HIV}^{+} .{ }^{*} P<0.05$.

tent for other IA markers tested, which exhibited increased frequency in $\mathrm{CD} 4^{+} \mathrm{T}$ cells and not $\mathrm{CD} 8^{+} \mathrm{T}$ cells (except HLA-DR) in $\mathrm{HIV}^{+}$compared with HC. These data demonstrate the dominant effect of HIV on IA over biological age and show that while virologic control with cART is able to normalize IA in $\mathrm{CD} 8^{+} \mathrm{T}$ cells, IA persists in $\mathrm{CD}^{+} \mathrm{T}$ cells in $\mathrm{HIV}^{+}$virologically suppressed patients. We also found that levels of IA on $\mathrm{CD}^{+} \mathrm{T}$ cells were not associated with duration of ART treatment (data not shown), suggesting that persistent IA on $\mathrm{CD}^{+} \mathrm{T}$ cells may be irreversible and the time of treatment initiation relative to infection (e.g., during acute infection) may be key in determining IA, as has been suggested previously (5).

An important question we wanted to address with the current study was whether any of the variables associated with biological age, IA, and inflammation, were predictive of influenza vaccine $\mathrm{Ab}$ responses. In a previous study of postmenopausal women with and without HIV, significantly reduced levels of postvaccination immunological measures (i.e., memory B cell and pTfh expansion, pTfh IL- $21^{+}$frequencies) were observed in $\mathrm{HIV}^{+}$compared with HIV negative, leading to the conclusion that HIV exacerbated age-related immune defects, even though frequencies of responders to H1N1 were not different between the 2 groups (22). Additionally, prevaccination CD4 IA showed a positive correlation with age and inverse correlation with H1N1 response, which formed the basis of our questions regarding baseline IA and vaccine response for the current study.

The influenza strains included in the tri- or quadrivalent influenza vaccine are determined yearly based upon expected circulating strains of influenza; however, year-to-year variation in the TIV used was relatively low during the study period. The H1N1 pdm09 antigen has been present in the vaccine since the H1N1 influenza A pandemic in 2009, and H3N2 and B antigens were identical for the first 2 seasons of the study. The vast majority of individuals in our study exhibited seroprotective $\mathrm{Ab}$ titers $(>1: 40)$ to all antigens at baseline. The prevalence of existing humoral immune responses in the human population complicates use of the influenza vaccination model for determining immunological predictors of vaccine responsiveness. Nevertheless, many groups have used and continue to use the seasonal flu vaccine to probe immune competence and explore new biomarkers in order to improve vaccine design $(29,37-43)$. The use herein of absolute response and response score criteria facilitates comparisons without altering the conventional definitions for determining vaccine responder status.

Figure 7. Discrimination of influenza vaccine responders and nonresponders using LASSO-identified variables. Partial least squares discriminant analysis (PLSDA) plots are shown for (A) HIV-negative (HC) $(n=57)$ and (B) HIV+ $(n=64)$ absolute responders $(\Delta)$ and nonresponders $(0)$ based on the variables identified by LASSO in Table 4.

A HC PLSDA: Response Score

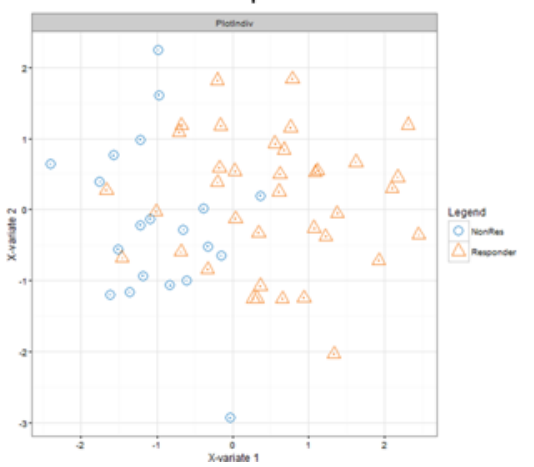

B

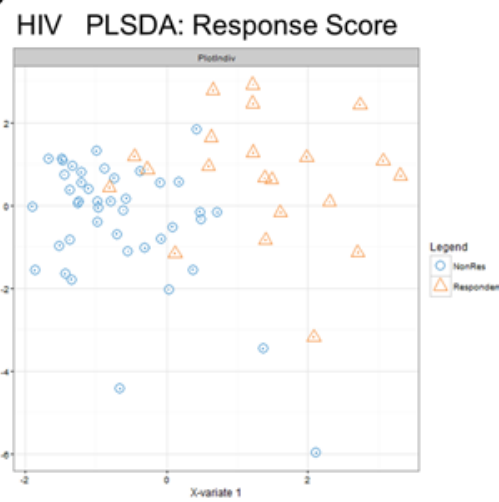


Table 4. Identification of variables associated with influenza vaccine response using LASSO

\begin{tabular}{|c|c|c|c|}
\hline Estimate Std. & Error & $t$ value & $\operatorname{Pr}(>|t|)$ \\
\hline 6.0445 & 2.8724 & 2.104 & 0.04030 \\
\hline-0.9504 & 0.2782 & -3.416 & 0.00125 \\
\hline 0.6293 & 0.2603 & 2.417 & 0.01925 \\
\hline 0.9858 & 0.3962 & 2.488 & 0.01614 \\
\hline 0.7383 & 0.2763 & 2.672 & 0.01009 \\
\hline
\end{tabular}

\begin{tabular}{|c|c|c|c|c|}
\hline \multicolumn{5}{|l|}{ Variables associated with response score in HIV } \\
\hline & Estimate Std. & Error & $t$ value & $\operatorname{Pr}(>|t|)$ \\
\hline IL-21 & -0.16089 & 0.07367 & -2.184 & 0.033509 \\
\hline TCM (\% of CD4) & 0.87210 & 0.30730 & 2.838 & 0.006461 \\
\hline CD38+HLA-DR+ICOS+Ki-67+PD-1+ (\% of pTfh) & -3.13382 & 1.06869 & -2.932 & 0.004991 \\
\hline CD38+HLA-DR+ICOS+Ki-67+PD-1- (\% of pTfh) & 12.24164 & 3.90059 & 3.138 & 0.002798 \\
\hline CD38+HLA-DR-ICOS-Ki-67+PD-1+ (\% of pTfh) & -90.06714 & 34.09332 & -2.642 & 0.010868 \\
\hline CD38-HLA-DR- (\% of CD8) & 0.92365 & 0.23533 & 3.925 & 0.000256 \\
\hline
\end{tabular}

Residual standard error: 1.094 on 55 degrees of freedom. Multiple $\mathrm{R}^{2}: 0.4789$, adjusted $\mathrm{R}^{2}: 0.4031$. F statistic: 6.318 on 8 and 55 degrees of freedom, $P$ value: $8.669 \times 10^{-6}$.

The LASSO method has been used to identify key variables from large, complex data sets contributing to particular outcomes such as protective HIV vaccine Ab profiles (44) and spontaneous control of HIV disease (45). Here, we used LASSO to resolve predictors of serological responses to TIV in HIV ${ }^{+}$ and HC individuals. The results showed that certain markers of IA are associated with reduced influenza vaccine responses, as we expected, although only in the $\mathrm{HIV}^{+}$group. One of these markers, soluble $\mathrm{CD} 25$, is a general marker of IA and is elevated in diabetes, autoimmune disease, cancer, and immunodeficiency diseases (46). We previously showed that plasma SCD25 is elevated in $\mathrm{HIV}^{+}$compared with $\mathrm{HC}$ postmenopausal women (47). Although $\mathrm{sCD} 25$ showed a positive correlation with age in $\mathrm{HC}$, it was selected as a significant negative predictor of vaccine response in the HIV+ group only. All CD4, CD8, and pTfh flow cytometry variables were loaded into LASSO analysis (Supplemental Table 2) and interestingly, the pTfh cell subset stood out with meaningful associations with vaccine response in both HC and $\mathrm{HIV}^{+}$. Within germinal centers in lymph nodes, Tfh cells produce IL-21 and provide a number of signals to B cells through cell-surface receptor-ligand interactions. Although $\mathrm{pTfh}$ frequencies were similar between $\mathrm{HC}$ and $\mathrm{HIV}^{+}$, IL-21 levels in plasma were significantly reduced in $\mathrm{HIV}^{+}$compared with $\mathrm{HC}$, especially in the young and middle age groups, and paradoxically we found that baseline plasma IL-21 levels were negatively associated with vaccine response in the $\mathrm{HIV}^{+}$group only. In a previous study in $\mathrm{HIV}^{+}$children we found that baseline levels of $I L 21 R$ gene expression in $\mathrm{pTfh}$ were negatively associated with vaccine response to $\mathrm{H} 1 \mathrm{~N} 1$ (38). The relevance of these data are unclear and may point to aberrant IL-21 signaling in $\mathrm{HIV}^{+}$individuals that may be inhibitory for immune function and especially Tfh-mediated $\mathrm{B}$ cell responses to vaccination. Induction of IL-21 following vaccination may be a more relevant biomarker, as IL-21-producing $\mathrm{CD}^{+} \mathrm{T}$ cells in the circulation, recognized as $\mathrm{pTfh}$, have been shown to correlate with $\mathrm{Ab}$ responses to vaccination $(22,48,49)$. We found an association of pTfh frequency with vaccine response in $\mathrm{HC}$, while in $\mathrm{HIV}^{+}$, specific IA marker expression on pTfh was predictive and cell frequency was not associated. Of the 5 IA markers evaluated using Boolean gating on pTfh cells, PD-1 expression was clearly associated with low Ab response to TIV. Coexpression of CD38 and Ki-67 was required for the observed negative association, while $\mathrm{PD}-1-$ negative $\mathrm{pTfh}$ cells coexpressing ICOS and HLA-DR showed positive associations with TIV response. Collectively, these data substantiate previous 
findings that functional defects in pTfh cells present prior to vaccination in HIV-infected individuals on cART contribute to poor vaccine-induced $\mathrm{Ab}$ production $(38,50)$ and support peripheral Tfh cells as a promising biomarker for assessing immune function and potential for $\mathrm{Ab}$ response in response to vaccination. The PD-1/PD-L1 signaling axis between T/B cells has recently been implicated in dysregulated $\mathrm{B}$ cell function and $\mathrm{Ab}$ response to TIV by our group (28). Indeed, the finding of PD-1, an immune checkpoint molecule, as a predictive marker on pTfh provides a potential target for intervention given the therapeutic successes of checkpoint-inhibitor drugs, and strategies targeting this pathway may lead to improved immune function in $\mathrm{HIV}^{+}$individuals.

The $\mathrm{CD}^{+} / \mathrm{CD}^{+} \mathrm{T}$ cell ratio has been shown to correlate with immune function in a number of clinical settings, especially in HIV infection. The volunteer population in this study matched other cohorts exhibiting reduced $\mathrm{CD} 4^{+} \mathrm{T}$ cell absolute counts and $\mathrm{CD} 4^{+} / \mathrm{CD} 8^{+}$ratios and increased $\mathrm{CD} 8^{+} \mathrm{T}$ cell counts in cART-treated $\mathrm{HIV}^{+}$individuals compared with $\mathrm{HC}$ (51), although neither of these variables were selected in LASSO analysis for prediction of vaccine response in $\mathrm{HIV}^{+}$. In $\mathrm{HC}$, however, $\mathrm{CD}^{+} \mathrm{T}$ cell counts were selected as a negative predictor of response. A decline in $\mathrm{CD}^{+} \mathrm{T}$ cell count with age in HIVnegative individuals has been documented previously (52); although our data did not reach significance for the correlation between $\mathrm{CD}^{+} \mathrm{T}$ cell count and age, there was a downward trend. The data shown here suggest that $\mathrm{CD} 8^{+} \mathrm{T}$ cell counts may be a more specific marker of immune dysfunction than $\mathrm{CD} 4^{+}$ $\mathrm{T}$ cell count or the ratio in $\mathrm{HC}$. In line with results showing an increase in PD-1 with age on CD8 ${ }^{+} \mathrm{T}$ cells in $\mathrm{HC}$ (Table 2), we found a moderate negative association of PD-1 expression on CD8 ${ }^{+} \mathrm{TEM}$ with vaccine response score ( $r=-0.31, P=0.0002$, data not shown), which could contribute to the impact of $\mathrm{CD}^{+} \mathrm{T}$ cell count observed in Table 4 . Despite the differences in $\mathrm{T}$ cell counts between $\mathrm{HC}$ and $\mathrm{HIV}^{+}$, the changes in distribution of $\mathrm{T}$ cell maturation subsets with age were largely conserved in the context of cART-treated HIV infection, with the exception of CD4+ TCM and TTM which demonstrated differential relationships with aging in $\mathrm{HIV}^{+}$and $\mathrm{HC}$. In $\mathrm{HIV}^{+}$, TTM increased with age and showed no change in TCM, while the opposite pattern was observed in HC. This subtle difference in the memory compartment may indicate a decreased potential for proliferation, self-renewal, and lymphoid homing of $\mathrm{CD}^{+} \mathrm{T}$ cells in aging $\mathrm{HIV}^{+}$individuals (53). TCM frequency was positively associated with vaccine response in $\mathrm{HIV}^{+}$, lending further support to this hypothesis.

Plasma levels of CRP, D-dimer, and IL-6 have all been shown to be biomarkers of non-AIDS comorbidities in HIV-infected individuals, even those on cART (52). In our study population, CRP and D-dimer levels did not exhibit linear relationships with age in either $\mathrm{HC}$ or $\mathrm{HIV}^{+}$, although they did show increased levels in the middle and old groups compared with young (Supplemental Figure 1). Interestingly, IL-6 levels were reduced in the $\mathrm{HIV}^{+}$group compared with $\mathrm{HC}$. These data suggest that biomarkers for Ab response to vaccination differ from those involved in comorbid health events such as malignancy, nonaccidental mortality, cardiovascular disease, and stroke.

Overall, our data demonstrate that HIV-related immune senescence, which is age independent and characterized by increased IA expression on $\mathrm{CD}^{+} \mathrm{T}$ cells, is distinct from biological aging. Further, in terms of evaluating immune response to vaccinations, the same variables were not predictive in both $\mathrm{HC}$ and $\mathrm{HIV}^{+}$ individuals, so it will be necessary to consider these populations separately in regards to vaccine strategies. In the case of $\mathrm{HC}$, expansion of pTfh cells could improve vaccine response, while in $\mathrm{HIV}^{+}$it will be important to modify the quality of pTfh in order to improve the outcome. The use of animal models such as humanized mouse models and nonhuman primate models for HIV may be useful to test interventions for boosting immune function $(54,55)$. Future studies should aim to understand how pTfh function is affected by persistent IA and inflammation in HIV-infected individuals with a focus on antigen-specific pTfh.

\section{Methods}

Study volunteers. Study participants were recruited from University of Miami, Jackson Memorial, and VA Hospitals in Miami, FL. Participants were recruited in 2 populations: (a) 140 HIV-infected, cART-treated individuals who demonstrated virus suppression (HIV RNA $<40$ copies $/ \mathrm{ml}$ ) for at least 1 year prior to enrollment, and (b) $141 \mathrm{HIV}$-uninfected healthy controls. Individuals were enrolled concurrently from 3 age groups: young (18-39 years), middle age (40-59 years), and old (60 years or older). Table 1 shows sex, race, ethnicity, and duration of ART data for each applicable participant group. Peripheral blood mononuclear cells (PBMCs) and plasma were stored in liquid nitrogen and $-80^{\circ} \mathrm{C}$ freezers, respectively, until further experiments were performed. 
Ethics statement. The study was approved by the University of Miami Institutional Review Board. Voluntary signed informed consent was obtained from every participant prior to participating in the study.

Influenza vaccine study. All participants were administered the seasonal influenza TIV and provided peripheral blood samples at prevaccination (T0) and postvaccination time points: day 7 (T1), day 21 (T2), and week 24 (T3). Serum titers for Abs against each vaccine strain were determined at every time point by hemagglutination inhibition assay as described previously (56). Individual vaccine strain antigens were provided as gifts from Giuseppe del Giudice (Novartis, Siena, Italy). For the 2013-2014 and 2014-2015 seasons the 3 strains in the vaccine were H1N1 A/California/7/2009, H3N2 A/Texas/50/2012, and B/ Massachusetts/02/2012-like. For the 2015-2016 season the 3 strains were H1N1 A/California/7/2009, H3N2 A/Switzerland/9715293/2013, and B/Phuket/3073/2013.

Multiparameter flow cytometry. Cryopreserved PBMCs were thawed in groups of 18 study participants at a time, randomized by group affiliation (HIV status and age group). Thawed PBMCs were rested overnight in RPMI including 10\% fetal bovine serum, then washed and stained with LIVE/DEAD Fixable Aqua Dead Cell Stain Kit (Thermo Fisher Scientific) prior to labeling for cell surface and intracellular protein expression using commercially available fluorescent marker-conjugated mAbs. IA markers were evaluated in T cell subsets in 1 tube containing the following Abs against cell surface antigens obtained from BD Biosciences: CD3 (564001/clone SK7), CD4 (552838/clone L200), CD8 (561453/clone RPA-T8), CD45RO (561137/clone UCHL1), CCR7 (562381/clone 150503), CXCR5 (558113/clone RF8B2), CD38 (555460/ clone HIT2), and PD-1 (564104/clone EH12.1). The following additional Abs were obtained from Biolegend: HLA-DR (307604/clone L243) and ICOS (313524/clone C398.4A). Anti-CD27 (15-0279-41/clone 323) was obtained from eBiosciences. Following surface labeling, cells were permeabilized and fixed using BD Cytofix/Cytoperm and labeled for intracellular expression of Ki-67 (350516/clone Ki-67 from Biolegend). Samples were fixed with $1 \%$ paraformaldehyde in PBS and stored at $4^{\circ} \mathrm{C}$ for up to 24 hours before acquisition on a BD Fortessa instrument. Flow cytometry data were analyzed manually using FlowJo V10 (Tree Star, Inc.).

Plasma assays. Plasma levels of sCD14, sCD163, sCD25, sTNFRI, sTNFRII, and CRP were determined using the Human Quantikine Immunoassay (R\&D Systems) following the manufacturer's instructions. For sCD14 measurement, samples were diluted 400 -fold and results are expressed in pg/ml. For sCD163 measurement, samples were diluted 30-fold and results are expressed in pg/ml. For sCD25 measurement, samples were diluted 4-fold and results are expressed in pg/ml. For sTNFRI and sTNFRII measurement, samples were diluted 10-fold and results are expressed in pg/ml. For CRP measurement, samples were diluted 200-fold and results are expressed as pg/ml. IL-21 plasma levels were determined on undiluted samples (Biolegend) and results are expressed in $\mathrm{pg} / \mathrm{ml}$. BNP plasma levels were determined on undiluted samples (Eagle Biosciences) and results are expressed in pmol/ml. Neopterin plasma levels were determined on undiluted samples (IBL) and results are expressed in pg/ml. For D-dimer measurement (Sekisui), plasma samples were diluted 50-fold and results are expressed in $\mathrm{pg} / \mathrm{ml}$.

LPS measurement. LPS levels were measured in plasma samples by the use of the Limulus amebocyte lysate chromogenic endpoint assay (Lonza Group Ltd) according to the manufacturer's recommendations. Samples were diluted 1:5 in endotoxin-free water and heat inactivated at $80^{\circ} \mathrm{C}$ for 10 minutes prior to the assay. LPS concentration in the samples was calculated in relation to an E. coli endotoxin standard and expressed in $\mathrm{pg} / \mathrm{ml}$.

Multiplex cytokine measurement. Plasma levels of cytokines were measured using a customized MILLIPLEX Human Cytokine magnetic bead panel (EMD Millipore) following the manufacturer's instructions. Briefly, plasma samples were thawed, vortexed, and centrifuged at 1,000 $\mathrm{g}$ for 3 minutes immediately prior to testing. Undiluted plasma was incubated overnight with a mixture of beads specific for IL-6, IL-8, IL$17 \mathrm{~A}, \mathrm{IFN}-\gamma, \mathrm{MCP}-1$, and TNF- $\alpha$ at $4^{\circ} \mathrm{C}$ with shaking. Plasma s-ICAM1 and sVCAM- 1 were measured in the same manner using a customized MILLIPLEX Human Neurodegenerative Disease magnetic bead panel (EMD Millipore). After washing, the beads were incubated with biotinylated detection Abs for 1 hour at room temperature. Streptavidin-PE was then added to the wells and allowed to incubate for 30 minutes at room temperature. The beads were then washed and diluted with $150 \mu 1$ Sheath Fluid before acquisition on a MAGPIX instrument (Luminex Corporation). The mean fluorescence intensity (MFI) data were analyzed with MILLIPLEX Analyst Software V.3.5 (EMD Millipore). Cytokine concentrations were determined based on standard curves and expressed in $\mathrm{pg} / \mathrm{ml}$.

Determining serological response to influenza vaccine. The serological response to each vaccine strain was defined as a 4-fold or greater increase in titer at $\mathrm{T} 2$ relative to $\mathrm{T} 0$. We used the term absolute responder to identify participants with a 4-fold or greater increase in serum titer for all 3 strains and absolute nonresponder 
to identify participants with a less than 4-fold increase in titer for all 3 strains. The term "other" identifies participants who responded to 1 or 2 antigens only. A response score was determined for each participant for use in correlation analysis with flow cytometry and plasma biomarker data sets using the following formula: score $=\log 2$ (H1N1 fold change T2/T0 + H3N2 fold change T2/T0 + B fold change T2/T0). The score allowed us to combine responses from all 3 strains into 1 data point while retaining information regarding magnitude of response to 1 or more strains.

Statistics. All data sets were loaded into Prism version 7.00 for Windows (GraphPad Software) and variables related to $\mathrm{T}$ cell counts, multiparameter flow cytometry data, and plasma biomarkers were evaluated for associations with biological age using Pearson correlation analyses and by age group between $\mathrm{HC}$ and $\mathrm{HIV}^{+}$using a 2-tailed Student's $t$ test. A $P$ value less than 0.05 was considered significant. Box-and-whisker plots were generated in Prism and the bounds of the box extends from the 25th to 75th percentile and the line inside the box is the median value. The whiskers represent minimum and maximum values. Pair-wise correlation matrix analysis was implemented using the $\mathrm{R}$ package corrgram and variables in the correlogram were ordered using the principal component analysis. For association of variables with influenza vaccine response, 131 variables listed in Supplemental Table 2 were $\log 2$ transformed and loaded into R package glmnet for LASSO analysis to fit a generalized linear model via penalized maximum likelihood and regression regulated at $\alpha=1$ (57). Ordinary least squares was performed on LASSO lambdaMin-selected variables to reveal the association with response score and partial least squares discriminant analysis (PLSDA) was performed to predict categorical response (responders, nonresponders) using $\mathrm{R}$ package mixOmics (58). Note: In our data set, individuals with very high baseline titers $(>1: 320)$ were always characterized as nonresponders due to the inability to reach a 4-fold increase above baseline; therefore, we implemented a cutoff of 1:320 for baseline titer for participants to be included in the LASSO modeling analysis.

Study approval. All subjects (Table 1) were deidentified and provided written informed consent according to protocols approved by IRB of the University of Miami in accordance with the Declaration of Helsinki.

\section{Author contributions}

LDA, S. Pallikkuth, VG, SR, RP, and S. Pahwa provided intellectual input and contributed to the experimental design. LDA, S. Pallikkuth, VG, and SR performed the experiments. KLA and SR performed statistical analysis. LDA, S. Pallikkuth, and S. Pahwa wrote the manuscript. S. Pahwa was responsible for the overall design and conduct of the study.

\section{Acknowledgments}

This work was supported by a National Institutes of Allergy and Infectious Diseases grant awarded to S. Pahwa (RO1AI108472) and made possible through support for the Miami Center for AIDS Research (CFAR) at the University of Miami Miller School of Medicine funded by a grant (P30AI073961) from the NIH, which is supported by the following NIH Co-Funding and Participating Institutes and Centers: NIAID, NCI, NICHD, NHLBI, NIDA, NIMH, NIA, NIDDK, NIGMS, FIC, and OAR. The content is solely the responsibility of the authors and does not necessarily represent the official views of the NIH.

The authors would like to thank all study participants for their time and cooperation and the following clinicians for patient recruitment: Margaret Fischl, Gordon Dickinson, Allan Rodriguez, and Maria Alcaide. We thank Margaret Roach, Maria Pallin, Celeste Sanchez, Sidney Lane, and Anil Mahavadi for technical assistance in this study; and Louis Gonzalez, Katherine Klose, Valeria Boter, and the Clinical Research Center at University of Miami Hospital for assistance recruiting and managing study participants. We thank Li Pan for statistical analysis.

Address correspondence to: Savita Pahwa, Miami Center for AIDS Research (CFAR), Department of Microbiology and Immunology, University of Miami Miller School of Medicine, 1580 NW 10th Avenue BCRI Building, Seventh floor, Miami, Florida 33136, USA. Phone: 305.243.8125; Email: spahwa@med.miami.edu.

1. Deeks SG. HIV infection, inflammation, immunosenescence, and aging. Annu Rev Med. 2011;62:141-155.

2. Gross AM, et al. Methylome-wide analysis of chronic HIV infection reveals five-year increase in biological age and epigenetic targeting of HLA. Mol Cell. 2016;62(2):157-168.

3. Horvath S, Levine AJ. HIV-1 infection accelerates age according to the epigenetic clock. J Infect Dis. 2015;212(10):1563-1573. 
4. Serrano-Villar S, et al. HIV-infected individuals with low CD4/CD8 ratio despite effective antiretroviral therapy exhibit altered $\mathrm{T}$ cell subsets, heightened $\mathrm{CD} 8^{+} \mathrm{T}$ cell activation, and increased risk of non-AIDS morbidity and mortality. PLoS Pathog. 2014;10(5):e1004078.

5. Hunt PW, Lee SA, Siedner MJ. Immunologic biomarkers, morbidity, and mortality in treated HIV infection. J Infect Dis 2016;214 Supp1 2:S44-S50.

6. Pallikkuth S, Fischl MA, Pahwa S. Combination antiretroviral therapy with raltegravir leads to rapid immunologic reconstitution in treatment-naive patients with chronic HIV infection. J Infect Dis. 2013;208(10):1613-1623.

7. Duprez DA, et al. Inflammation, coagulation and cardiovascular disease in HIV-infected individuals. PLoS One. 2012;7(9):e44454.

8. Kuller LH, et al. Inflammatory and coagulation biomarkers and mortality in patients with HIV infection. PLoS Med 2008;5(10):e203.

9. Brenchley JM, et al. Microbial translocation is a cause of systemic immune activation in chronic HIV infection. Nat Med. 2006;12(12):1365-1371.

10. Jiang W, et al. Plasma levels of bacterial DNA correlate with immune activation and the magnitude of immune restoration in persons with antiretroviral-treated HIV infection. J Infect Dis. 2009;199(8):1177-1185.

11. Ramirez CM, et al. Immunologic profiles distinguish aviremic HIV-infected adults. AIDS. 2016;30(10):1553-1562.

12. Karim R, et al. Association of HIV clinical disease progression with profiles of early immune activation: results from a cluster analysis approach. AIDS. 2013;27(9):1473-1481.

13. Prince HE, Jensen ER. Three-color cytofluorometric analysis of CD8 cell subsets in HIV-1 infection. J Acquir Immune Defic Syndr. 1991;4(12):1227-1232.

14. Hunt PW, et al. Relationship between $\mathrm{T}$ cell activation and $\mathrm{CD} 4^{+} \mathrm{T}$ cell count in HIV-seropositive individuals with undetectable plasma HIV RNA levels in the absence of therapy. J Infect Dis. 2008;197(1):126-133.

15. Naylor K, et al. The influence of age on T cell generation and TCR diversity. J Immunol. 2005;174(11):7446-7452.

16. Pulko V, et al. Human memory T cells with a naive phenotype accumulate with aging and respond to persistent viruses. Nat Immunol. 2016;17(8):966-975.

17. Ferguson FG, Wikby A, Maxson P, Olsson J, Johansson B. Immune parameters in a longitudinal study of a very old population of Swedish people: a comparison between survivors and nonsurvivors. J Gerontol A Biol Sci Med Sci. 1995;50(6):B378-B382.

18. Franceschi C, et al. Inflamm-aging. An evolutionary perspective on immunosenescence. Ann N Y Acad Sci. 2000;908:244-254.

19. Harris TB, et al. Associations of elevated interleukin-6 and C-reactive protein levels with mortality in the elderly. Am JMed. 1999;106(5):506-512.

20. Liang SY. Sepsis and other infectious disease emergencies in the elderly. Emerg Med Clin North Am. 2016;34(3):501-522.

21. Haq K, McElhaney JE. Ageing and respiratory infections: the airway of ageing. Immunol Lett. 2014;162(1 Pt B):323-328.

22. George VK, et al. HIV infection worsens age-associated defects in antibody responses to influenza vaccine. $J$ Infect Dis. 2015;211(12):1959-1968.

23. Lu W, Mehraj V, Vyboh K, Cao W, Li T, Routy JP. CD4:CD8 ratio as a frontier marker for clinical outcome, immune dysfunction and viral reservoir size in virologically suppressed HIV-positive patients. J Int AIDS Soc. 2015;18:20052.

24. Day CL, et al. PD-1 expression on HIV-specific T cells is associated with T-cell exhaustion and disease progression. Nature. 2006;443(7109):350-354.

25. Dong C, et al. ICOS co-stimulatory receptor is essential for T-cell activation and function. Nature. 2001;409(6816):97-101.

26. Antonelli LR, et al. Elevated frequencies of highly activated CD4+ $\mathrm{T}$ cells in $\mathrm{HIV}^{+}$patients developing immune reconstitution inflammatory syndrome. Blood. 2010;116(19):3818-3827.

27. Leng Q, Borkow G, Weisman Z, Stein M, Kalinkovich A, Bentwich Z. Immune activation correlates better than HIV plasma viral load with CD4 T-cell decline during HIV infection. J Acquir Immune Defic Syndr. 2001;27(4):389-397.

28. Rinaldi S, et al. Paradoxical aging in HIV: immune senescence of B Cells is most prominent in young age. Aging (Albany NY). 2017;9(4):1307-1325

29. Nakaya HI, et al. Systems analysis of immunity to influenza vaccination across multiple years and in diverse populations reveals shared molecular signatures. Immunity. 2015;43(6):1186-1198.

30. Frasca D, Blomberg BB. B cell function and influenza vaccine responses in healthy aging and disease. Curr Opin Immunol. 2014;29:112-118.

31. Tibshirani R. The lasso method for variable selection in the Cox model. Stat Med. 1997;16(4):385-395.

32. Haynes BF, Markert ML, Sempowski GD, Patel DD, Hale LP. The role of the thymus in immune reconstitution in aging, bone marrow transplantation, and HIV-1 infection. Annu Rev Immunol. 2000;18:529-560.

33. Sherman GG, et al. CD38 expression on CD8(+) T cells as a prognostic marker in vertically HIV-infected pediatric patients. Pediatr Res. 2002;51(6):740-745.

34. Liu Z, Cumberland WG, Hultin LE, Prince HE, Detels R, Giorgi JV. Elevated CD38 antigen expression on CD8 ${ }^{+} \mathrm{T}$ cells is a stronger marker for the risk of chronic HIV disease progression to AIDS and death in the Multicenter AIDS Cohort Study than $\mathrm{CD}^{+}$cell count, soluble immune activation markers, or combinations of HLA-DR and CD38 expression. J Acquir Immune Defic Syndr Hum Retrovirol. 1997;16(2):83-92.

35. Vigano A, Saresella M, Villa ML, Ferrante P, Clerici M. CD $38^{+} \mathrm{CD} 8^{+} \mathrm{T}$ cells as a marker of poor response to therapy in HIVinfected individuals. Chem Immunol. 2000;75:207-217.

36. Sachdeva M, Fischl MA, Pahwa R, Sachdeva N, Pahwa S. Immune exhaustion occurs concomitantly with immune activation and decrease in regulatory T cells in viremic chronically HIV-1-infected patients. J Acquir Immune Defic Syndr. 2010;54(5):447-454.

37. Tan Y, Tamayo P, Nakaya H, Pulendran B, Mesirov JP, Haining WN. Gene signatures related to B-cell proliferation predict influenza vaccine-induced antibody response. Eur J Immunol. 2014;44(1):285-295.

38. de Armas LR, et al. Induction of IL21 in peripheral T follicular helper cells is an indicator of influenza vaccine response in a previously vaccinated HIV-infected pediatric cohort. J Immunol. 2017;198(5):1995-2005.

39. Tsang JS, et al. Global analyses of human immune variation reveal baseline predictors of postvaccination responses. Cell. 2014;157(2):499-513. 
40. Haralambieva $\mathrm{IH}$, et al. The impact of immunosenescence on humoral immune response variation after influenza A/H1N1 vaccination in older subjects. PLoS ONE. 2015;10(3):e0122282.

41. Zimmermann MT, et al. Integration of immune cell populations, mRNA-Seq, and CpG methylation to better predict humoral immunity to influenza vaccination: dependence of mRNA-Seq/CpG methylation on immune cell populations. Front Immunol. 2017;8:445

42. Cagigi A, et al. Premature immune senescence during HIV-1 vertical infection relates with response to influenza vaccination. $J$ Allergy Clin Immunol. 2014;133(2):592-594.

43. Jürchott K, et al. Highly predictive model for a protective immune response to the A(H1N1)pdm2009 influenza strain after seasonal vaccination. PLoS ONE. 2016;11(3):e0150812.

44. Chung AW, et al. Dissecting polyclonal vaccine-induced humoral immunity against HIV using systems serology. Cell. 2015;163(4):988-998.

45. Ndhlovu ZM, et al. High-dimensional immunomonitoring models of HIV-1-specific CD8 T-cell responses accurately identify subjects achieving spontaneous viral control. Blood. 2013;121(5):801-811.

46. Litzman J, Nechvatalova J, Xu J, Ticha O, Vlkova M, Hel Z. Chronic immune activation in common variable immunodeficiency (CVID) is associated with elevated serum levels of soluble CD14 and CD25 but not endotoxaemia. Clin Exp Immunol. 2012;170(3):321-332.

47. Alcaide ML, et al. Immune activation in HIV-infected aging women on antiretrovirals--implications for age-associated comorbidities: a cross-sectional pilot study. PLoS One. 2013;8(5):e63804.

48. Schultz BT, et al. Circulating HIV-specific interleukin-21(+)CD4(+) T cells represent peripheral Tfh cells with antigen-dependent helper functions. Immunity. 2016;44(1):167-178.

49. Pallikkuth S, et al. Impaired peripheral blood T-follicular helper cell function in HIV-infected nonresponders to the 2009 H1N1/09 vaccine. Blood. 2012;120(5):985-993.

50. Herati RS, et al. Circulating CXCR5 ${ }^{+} \mathrm{PD}-1^{+}$response predicts influenza vaccine antibody responses in young adults but not elderly adults. J Immunol. 2014;193(7):3528-3537.

51. Cobos Jiménez V, et al. T-cell activation independently associates with immune senescence in HIV-infected recipients of longterm antiretroviral treatment. J Infect Dis. 2016;214(2):216-225.

52. Tenorio AR, et al. Soluble markers of inflammation and coagulation but not T-cell activation predict non-AIDS-defining morbid events during suppressive antiretroviral treatment. J Infect Dis. 2014;210(8):1248-1259.

53. Mahnke YD, Brodie TM, Sallusto F, Roederer M, Lugli E. The who's who of T-cell differentiation: human memory T-cell subsets. Eur J Immunol. 2013;43(11):2797-2809.

54. Seung E, Dudek TE, Allen TM, Freeman GJ, Luster AD, Tager AM. PD-1 blockade in chronically HIV-1-infected humanized mice suppresses viral loads. PLoS One. 2013;8(10):e77780

55. Pallikkuth S, et al. Interleukin-21 administration to rhesus macaques chronically infected with simian immunodeficiency virus increases cytotoxic effector molecules in T cells and NK cells and enhances B cell function without increasing immune activation or viral replication. Vaccine. 2011;29(49):9229-9238.

56. Parmigiani A, et al. Impaired antibody response to influenza vaccine in HIV-infected and uninfected aging women is associated with immune activation and inflammation. PLoS One. 2013;8(11):e79816.

57. Friedman J, Hastie T, Tibshirani R. Regularization paths for generalized linear models via coordinate descent. J Stat Softw. 2010;33(1):1-22.

58. Pérez-Enciso M, Tenenhaus M. Prediction of clinical outcome with microarray data: a partial least squares discriminant analysis (PLS-DA) approach. Hum Genet. 2003;112(5-6):581-592. 